\title{
COMMISSION 46: THE TEACHING OF ASTRONOMY
}

\author{
PRESIDENT: J.R. PERCY
}

VICE-PRESIDENT: J. FIERRO

ORGANIZING COMMITTEE: J.R. Percy, J. Fierro, A.H. Batten, A. Arellano Ferro, M. Gerbaldi, L. Gouguenheim, W. Gutsch, D. Hoff, S. Isobe, D. McNally, J. Narlikar, A.J. Norton, J.M. Pasachoff, D.G. Wentzel.

\section{Introduction}

Education is important to astronomers because it affects the recruitment and training of future astronomers, and because it affects the awareness, understanding, and appreciation of astronomy by taxpayers and politicians.

There are many other reasons why astronomy should be part of education and culture. Astronomy is deeply rooted in the history of almost every society, as a result of its practical applications and its philosophical implications. It still has everyday applications to calendars and timekeeping, navigation, seasons and climate. It has longer-term applications to climate change and biological extinctions. Astronomy advances the other sciences, and is a dynamic science in its own right. It deals with our place in time and space, our cosmic roots, and our kinship with other peoples and species on earth. It reveals a universe which is vast, varied, and beautiful, and it promotes curiosity, imagination, and a sense of shared exploration and discovery. It provides an enjoyable hobby for millions of people. In a school context, it provides an alternative approach to the scientific method - the observational (as opposed to experimental) approach. It can attract young people to study science and technology. It can promote rational thinking, and it can increase public interest in science and technology. These benefits are important in all countries, both developed and developing.

\section{Programs and Projects of Commission 46}

\subsection{INTRODUCTION}

Commission 46 is a special committee of the IAU Executive Committee, whose purpose is "to further the development and improvement of astronomical education at all levels, throughout the world". Its membership includes the Organizing Committee, who are responsible for specific programs and projects, the National Representatives, and others with a special interest in education. There are also "liaison people" in many of the countries which are involved in astronomy, but are not yet affiliated with the IAU. Commission 46 is indebted to all of these individuals for the time, effort, and thought which they devote to astronomy education, and to their institutions for supporting their work.

\subsection{ORGANIZATION}

The Organizing Committee consists of J.R. Percy (Canada; President), J. Fierro (Mexico; Vice-President), A.H. Batten (Canada), A. Arellano Ferro (Mexico), M. Gerbaldi (France), L. Gouguenheim (France), W. Gutsch (USA), D. Hoff (USA), S. Isobe (Japan), D. McNally (UK), J. Narlikar (India), A.J. Norton (UK), J.M. Pasachoff (USA) and D.G. Wentzel (USA).

\subsection{MEETINGS}

As part of the 1994 IAU General Assembly in The Hague, Netherlands, the Commission organized a one-day Joint Discussion on "Current Developments in Astronomy Education". The Proceedings were edited by J.R. Percy, and published in Highlights of Astronomy, Volume 10, 143-176. 
The Commission sponsored and organized IAU Colloquium 162, held in London, UK, July 8-12, 1996. The SOC was chaired by L. Gouguenheim, and the LOC was chaired by D. McNally. The host institutions were University College London, and The Open University. The Colloquium attracted 130 participants from 40 countries. The review papers and contributed papers were of a high standard, and covered a wide range of topics. The Proceedings are being edited by L. Gouguenheim, D. McNally, and J.R. Percy, and will be published by Cambridge University Press.

\subsection{TEACHERS' WORKSHOPS}

Also as part of the 1994 IAU General Assembly, a now-traditional one-day workshop was held for local schoolteachers. The workshop was organized by H. Lamers, and held at the University of Utrecht, a short distance from The Hague. Almost 200 teachers attended, most of them high school physics teachers.

For the first time, a teachers' workshop was organized as part of an IAU research colloquium Colloquium 155 (Astrophysical Applications of Stellar Pulsation) in Cape Town, South Africa. It was organized by J.R. Percy and P.A. Whitelock; the presenters included both visiting astronomers, and local astronomers and educators. The workshop attracted a diverse and enthusiastic group of almost 100 teachers. Activities for teachers, amateur astronomers, and the public, were also held as part of the IAU Regional Meeting in Korea, in August 1996, as well as at other regional meetings in the past.

\subsection{INTERNATIONAL SCHOOLS FOR YOUNG ASTRONOMERS (ISYA);} D.G. WENTZEL AND M. GERBALDI

Since the last report, three ISYA have been organized and held successfully.

The 20th ISYA met at Inter-University Center for Astronomy and Astrophysics (IUCAA) January 3 - 21, 1994. IAU, UNESCO and ICSU provided travel support. The director of the school, Dr. J. Narlikar, asked seven faculty members to join the school: P. Eggleton (UK, stellar interiors and evolution), S. Isobe (Japan, observational techniques), M. Gerbaldi (France, stellar spectroscopy), D. Wentzel (USA, solar physics and MHD) and, from Pune: T. Padmanabhan (cosmology), A. K. Khembavi and D. J. Saikia (active galaxies and quasars). There were 35 participants, including 11 women. 25 foreign participants came from Korea, Vietnam, Nepal, Sri Lanka, Turkey, Iran, Ukraine, Russia, Bulgaria, Ireland, Canada and Argentina. 15 foreign participants, including 8 women, received travel support. The language was English. Lectures were supplemented by practical exercises including sky observing and science talks by 10 participants.

The 21st ISYA met in Egypt September 18 - October 8, 1994, the first and third weeks at Cairo University, the second week at Kottamia Observatory. Egyptian sponsors were the Academy of Scientific Research and Technology, the Ministry of Scientific Research, the National Research Institute for Astronomy and Geophysics, Cairo University, and the Ministry of International Cooperation. The Director of the School, Prof. R. A. Ghobros, invited four foreign faculty: J. Narlikar (India, cosmology), G. Longo (Italy, galaxies), M. Gerbaldi (France, stellar atmospheres), D. Wentzel (USA, solar physics and MHD) and, from Egypt: M. I. Wanas (cosmology), S. M. Hassan (star clusters, galactic structure), and M. S. El-azm and A. I. Basuni (observations with the $1.88 \mathrm{~m}$ telescope, spectroscopy and variable stars, respectively). There were 41 participants, including 10 women, with foreign participants (all receiving travel support) from Zambia, Nigeria, Algeria, Libya, Bulgaria, Slovakia, Uzbekhistan, Azerbeijan, Ukraine, Russia, Greece and Vietnam. The language was English. Several participants outlined their research. (Cf. IAU Information Bulletin No. 74).

The 22nd ISYA met in Brazil July 9 - 29, 1995, two weeks at the Federal University of Minas Gerais in Belo Horizonte, the third week at the Observatory Serra Piedade. Brazilian sponsors were the University, the Centre Nacional de Pesquisa, and FAPEMIG. The chair of the School's Organizing Committee was R. Las Casas. Faculty were C. Gullixson (USA, CCD detectors), J. Knude (Denmark, interstellar medium), R. Peletier (Netherlands, galaxies), J. Percy (Canada, teaching of astronomy, variable stars), B. Reipurt (Chile, star formation), S. Torres Peimbert (Mexico, practical astronomy), M. Gerbaldi (France, teaching of astronomy, practical astronomy) and from Brazil: L. P. Vaz (stellar evolution), S. Livi and R. Trevisan (teaching of astronomy). There were 38 participants including 15 women, with foreign participants from Argentina, Bolivia, Chile, Colombia, Cuba, Paraguay, Peru, Uruguay and Spain. Six nights were devoted to practical observations at the Observatory and three sessions on data reduction (Echelle spectra) were 
organized. Several participants gave short research talks. The languages of the School were Spanish and English. (Cf. IAU Information Bulletin No. 76).

The next ISYA is expected to be in Iran during July 1997.

\subsection{VISITING LECTURER PROGRAM (VLP); D.G. WENTZEL}

The sixth and last VLP course in Paraguay took place in the spring of 1994, with Dr. M. Bossi (Osservatorio Astronomico di Brera, Italy) as lecturer. Support was received from the Centro Latino-Americano de Fisica, and UNESCO, to cover the expenses of the lecturer, and the Societa Dante Alighierei provided an apartment for the lecturer in downtown Asuncion. Several "graduates" of the VLP in Paraguay are pursuing graduate studies in astronomy outside the country, or are otherwise active in astronomy.

\subsection{TEACHING FOR ASTRONOMICAL DEVELOPMENT (TAD); D. MCNALLY AND D.G. WENTZEL}

The IAU wishes to support institutions in countries that now have very little astronomy and who wish to expand their astronomy activities significantly. In the past, this goal has been expressed through the Visiting Lecturer Program, which operated in Peru and Paraguay. The revised program aims at a small number of additional countries. The IAU would primarily support the cost of travel needed for this program. (Cf. IAU Information Bulletin No. 74).

Announcements were sent to 19 appropriate countries. Applications were due January 2, 1996. Four applications were received and were reviewed by a committee of six astronomers. (Cf. IAU Information Bulletin No. 76).

The IAU Executive Committee approved, in principle, a two-year program focussing on a summer school in Vietnam, to re-introduce astronomy to that country after a 30-year hiatus, and an annual observing course in Honduras for students from six Central American countries, to support the development of astronomy in Central America.

\subsection{TRAVELLING TELESCOPE (TT); J.R. PERCY}

The Travelling Telescope is a Celestron- 8 telescope, with basic instrumentation, designed to provide astronomical facilities for institutions or countries which have not yet developed such facilities. Through the use of the TT, astronomers and students can gain exposure and experience which will help them to prepare proposals for facilities of their own.

In practice, the weight and delicacy of the telescope have made it very difficult and expensive to ship to developing countries. The instruments, however, are less of a problem. The instruments are currently in Paraguay, where they have been used for teaching and research on a local telescope as part of the VLP and its follow-up.

\subsection{NEWSLETTER (NL); J.R. PERCY AND A. ARELLANO FERRO}

The Newsletter publishes brief announcements and notes about the programs and projects of Commission 46 , and about other topics of general interest.

The following issues of the Newsletter have been distributed: No. 37 (November, 1993: Triennial Reports), No. 38 (November, 1993), No. 39 (June 1994), No. 40 (December, 1994), No. 41 (June, 1995), No. 42A and No. 42B (Fall-Winter, 1995-96), No. 43 (Summer, 1996). It is intended that the Newsletter will be distributed, electronically, four times a year, with paper copies being mailed, two issues at a time, twice a year. Because of the high cost of printing and mailing the paper copies, they will be sent only to the National Representatives, and to selected addresses which do not have easy access to electronic mail.

During the 1994 General Assembly, in The Hague, it was decided to implement the distribution of the Newsletter by electronic mail. The distribution has been made from the Department of Astronomy of the University of Guanajuato (Mexico), starting with the June 1995 issue.

The electronic Newsletter (ENL) is distributed to all members of Commission 46 and others who have provided an e-mail address. It is now sent to 505 individuals in 38 countries. It is also distributed to 190 libraries that have requested it.

The ENL is being sent in ascii format to ease the printing process of those who do not have TeX or LaTeX facilities. We would like to hear from those who do have such facilities, so that we can prepare 
a macro and distribute the ENL to them in LaTeX form. To receive the ENL, or to make comments or suggestions, please contact armando@astroscu.unam.mx or armando@cuevano.ugto.mx.

As a further means of informing and linking astronomy educators worldwide, Commission 46 is in the process of setting up a home page on the World Wide Web. A.J. Norton, The Open University, UK, has agreed to serve as "webmaster".

\subsection{TRIENNIAL REPORTS; J.R. PERCY, EDITOR}

The Triennial Reports are prepared by the National Representatives to Commission 46 or (in the case of countries not yet adhering to the IAU) by another liaison person. They contain one-page summaries of the present state of astronomy education in each country, and are published in the year preceding each General Assembly. These reports provide Commission 46 with information on the needs of each country, and they enable countries to benefit from the experiences of others. They also provide an interesting and enlightening perspective on astronomy education worldwide.

\subsection{SUBCOMMITTEE ON ECLIPSES; J.M. PASACHOFF}

Commission 46 has established a sub-committee to generate information on how countries (especially developing countries) can harness solar eclipses for educational and scientific benefit. The members are Professors B.R. Chou (School of Optometry, University of Waterloo, Canada), J. Fierro (Instituto de Astronomia, UNAM, Mexico), and J.M. Pasachoff (Williams College, USA; chair of the IAU Working Group on Solar Eclipses). Together, the sub-committee has a great deal of experience in solar research, safe solar observing, and public education. Specific and beneficial actions were taken in connection with the eclipse of October 1995, and plans are being made for forthcoming eclipses.

\subsection{RELATIONS WITH OTHER ORGANIZATIONS}

Commission 46 continues to work closely with other organizations with whom we share common interests. The IAU Working Group on the Worldwide Development of Astronomy, chaired by A.H. Batten, does much of the groundwork for our projects and programs, and it is often difficult to define where the work of one begins, and the other ends. Several members of our OC are also members of the WGWWDA.

Because of the importance of planetariums and science centres in astronomy education, Commission 46 has re-established contact with the International Planetarium Society by appointing $\mathrm{W}$. Gutsch to the Organizing Committee. It is hoped that the next IAU colloquium on astronomy education will include special sessions on the role of such facilities in both formal and informal education.

In 1993, ICSU established a Committee on Capacity Building in Science, which to some extent replaced the previous ICSU committee on which we were represented. M. Gerbaldi attended one meeting of the CCBS on our behalf, and we continue to maintain an active interest in its work.

The UN and ESA (European Space Agency) have sponsored a series of workshops on Basic Space Science, designed to integrate developing countries into modern space science and astronomy. These workshops led to follow-up projects such as the establishment of astronomical observatories in Sri Lanka, Colombia, and Honduras, the upgrade of the Kottamia telescope in Egypt, and the USA-Egypt-Russia Mars Drill Project. A.H. Batten, D. McNally, and J.R. Percy attended the Sixth UN/ESA Workshop on Basic Space Science, in Bonn in September 1996, at which it was decided that the workshops should continue. We have been involved in developing a booklet "Developing Astronomy and Space Science Worldwide", and a proposed manual on the role of small telescopes in education and research.

\subsection{BOOKS AND JOURNALS FOR DEVELOPING COUNTRIES; D. HOFF}

Commission 46 has established a sub-committee to develop a program to transfer surplus books and journals to institutions which are in need of them. We are very much aware of which institutions these are, and we have some ideas about sources of books and journals. We are now developing the process, and the sources of funds, which will make this program possible. 


\section{Other Developments in Astronomy Education}

\subsection{INTRODUCTION}

The Fifth International Conference on Teaching Astronomy was held in March 1995 in Vilanova i la Geltru, Spain. It was hosted by R.M. Ros, and the Universitat Politecnica de Catalunya (UPC). The Proceedings were edited by R.M. Ros, and published by the UPC. The Astronomical Society of the Pacific (ASP) organized a symposium on "Astronomy Education: Current Developments, Future Co-ordination" in June, 1995, in College Park, USA. The Proceedings were edited by J.R. Percy, and published as volume 89 of the ASP Conference Series.

The ASP's magazine Mercury publishes regular articles on both astronomy education, and international astronomy. There is not yet a publication which deals solely and specifically with astronomy education.

Another significant development was the founding, in 1995, of the European Association for Astronomy Education. This association now offers an efficient platform for astronomy educators at all levels - in particular, teachers - to interact in all related matters, including curriculum, teaching materials, student exchanges etc.

\subsection{SCHOOLS}

The major issues in school astronomy education, now being addressed around the world, include the following: (i) getting more and better astronomy into the curriculum; (ii) choosing content and teaching methods which are effective and appropriate for the students' stage of development; (iii) developing and implementing simple, "hands-on" activities; (iv) improving the training of teachers, both pre-service and in-service; (v) reaching under-served groups, including girls, the disadvantaged, and the disabled; (vi) making appropriate use of technology, such as computers (but keeping in mind that many schools do not have access to these); (vii) observing the sky in an increasingly light polluted world.

\subsection{UNIVERSITIES AND THE TRAINING OF ASTRONOMERS}

Many of the issues listed under "Schools", above, also apply to the university level. Most university instruction still relies on the lecture method. Implementing more and better lab and research activities is a priority. For the training of astronomers, access to books, journals, data, and equipment are important, especially for research projects. From the point of view of the students, however, the main concern is jobs - either in astronomy or elsewhere. Many academic and research positions are still filled by those hired in the 1960's and 1970's, and the number of new positions is generally small because of decreases in government spending. It is therefore beneficial if the students' training includes such useful skills as teaching, communication, computing, and even business, as well as mathematics and physics.

\subsection{PUBLIC EDUCATION}

Planetariums, science centres, and public observatories continue to play an important role in both formal and informal education. These facilities increasingly use "hands-on" exhibits and activities, and develop strong outreach programs to serve their various communities. There is an increasing emphasis on fundraising, and partnership with other public and private organizations, as government support decreases. Amateur astronomers continue to play an important role in this and other aspects of astronomy education.

The mass media play a dominant role in public education, and they strongly infuence students' interest and understanding of astronomy. The links between astronomy educators and the mass media are often weak or non-existent - a situation which needs to be addressed. 